\title{
CRIANÇAS DE TODO O MUNDO, UNI-VOS! ${ }^{1}$ NOTAS SOBRE A SUBMISSÃO DAS CRIANÇAS À "IDEOLOGIA DO TRABALHO ÚTIL"
}

\author{
Maria José Araújo² \\ Hugo Monteiro ${ }^{3}$
}

\begin{abstract}
RESUMO
A ideia de que as crianças vivem num mundo à parte, afastado da realidade social e política, sem tensões sociais e que constroem a sua identidade sem mesmo antes terem consciência da diversidade social, cultural,ambiental é uma visão etnocêntrica, cada vez mais difícil de aceitar. Considerada como um cidadão sob tutela e quase nunca como cidadão de pleno direito, a criança é privada da liberdade e da aventura que a natureza propõe,num mundo que não é para brincadeiras. Como bem explicitava John Dewey a educação é paradoxal e a antítese mais enraizada na história da educação está bem explicita entre a educação como preparação para o trabalho útil e a educação para uma vida de lazer no tempo livre. As simples expressões "trabalho útil" e "lazer" confirmam a afirmação de que a separação e o conflito de valores não se autocircunscrevem, mas refletem a divisão na vida social(2007), uma questão complexa que nos leva à proposta de debate neste texto.
\end{abstract}

Palavras chave: liberdade, trabalho, tempo livre, criança, brincar

\begin{abstract}
The idea that children live in a world apart, away from social and political reality, without social tensions and that they build their identity without even being aware of social, cultural or environmental diversity is an ethnocentric vision, very difficult to accept. Children are not always considered as full citizens and so they are deprived of the freedom and the adventure that nature offers, in a world that 'is not to play'. As John Dewey noticed, the most deeply rooted

\footnotetext{
${ }^{1}$ Os autores escrevem em língua portuguesa de Portugal.

${ }^{2}$ Doutorada em Ciências da Educação. Professora na Escola Superior de Educação do P. Porto-Portugal - E- mail: mjose@ese.ipp.pt

${ }^{3}$ Doutorado em Filosofia. Professor na Escola Superior de Educação P. Porto - Portugal. email: hugomonteiro@ese.ipp.pt
} 
antithesis in the history of education is the one between education as preparation for 'useful work' and education for 'leisure' in the free time. The simple expressions 'useful work' and 'leisure' confirm the assertion that segregation and conflict of values do not self-create, but reflect the division in social life (2007). This is the main purpose of this article.

Keywords: freedom, work, children, free time, play

\section{COM MARX POUCO SE BRINCA}

Em tempo de celebrações e de efemérides, de alusões e de alocuções fervorosamente ativistas ou pomposamente académicas, confirma-se a respeitabilidade austera do revolucionário de barba hirsuta a quem pouco imputariam qualquer vocação para interpelações à infância.

Para contrariar esta tendência, e não sem antes admitir o laconismo diretamente "educativo" do filósofo alemão, sublinhemos um dos preceitos basilares da sua filosofia da praxis: a sua orientação transformadora, ou a "crítica radical a toda a ordem existente" (MARX; ENGELS, 1976, p.94). A radicalidade desta crítica - a radicalidade de uma intenção transformadora veiculada na tão repetida $11^{\text {a }}$ tese sobre Feuerbach ${ }^{4}$ - alimenta-se também de uma leitura não linear do tempo e da temporalidade (BENSAID:2011,p.44), capaz de alastrar e desafiar toda a horda de leituras adultas que sucederam a Marx e que conduziram a acidentada história do marxismo.

Brincar com Marx, respeitando a letra e a energia revolucionária de Karl Marx, passa pois por levar muito a sério o seu apetite pela subversão da ordem existente, inclusive a séria maturidade das suas leituras, tementes da elevada respeitabilidade da sua barba encanecida. Brincar com Marx é ouvir o seu pensamento em contratempo (BENSAID, 2014, p.46).

Levemo-lo a sério. Façamos um pequeno introito rememorativo para, num passageiro minuto, reivindicar o espaço do brincar aos seus legítimos donos e soberanos.

\footnotetext{
4 "Os filósofos têm apenas interpretado o mundo de maneiras diferentes; a questão, porém, é transformá-lo", 11 a Tese de Feuerbach, de Karl Marx, http://ciml.250x.com/archive/marx_engels/portuguese/portuguese_marx_feuerbach_thesen_18 45.html, acesso 15.11.2018.
} 


\section{DE UMA IDEIA GERAL DE ALIENAÇÃO}

Reclamando a dinâmica de um novo materialismo, o ímpeto crítico de Marx revela-se no "caráter terreno" do pensamento, pelo modo como este se decide na horizontal dimensão da praxis (MARX, 1982,1). Aqui, Marx dá poucas ou nenhumas concessões a toda e qualquer movimentação especulativa que não permita que o pensamento - tudo o que é do pensamento, que é também tudo o que é de cada ser humano - se resolva ou decida fora do plano terreno, material ou práxico. Dirigindo-se à educação, na $3^{\underline{a}}$ tese sobre Feuerbach, Marx denuncia o beco sem saída na relação de implicação que coloca pura e simplesmente os seres humanos como produtos de circunstância e de educação. Se assim é - ou se assim é simplesmente como introduzir mudança, areia na engrenagem ou formas profundas de transformação?

Não basta essa constatação, assim como não chega alterar-se circunstâncias e educação para se chegar a condições de transformação. Contra Feuerbach - de certa forma contra Rousseau -, é preciso alterar toda a forma social para que a tentativa de sair deste círculo vicioso não resulte num beco sem saída. Porque são também os seres humanos quem criam as circunstâncias, pelo que só uma ilusória e alienante saída da sociedade permitiria encontrar condições para transformar essa sociedade. A simples conexão entre pessoa e circunstância revela-se no eixo de um circuito que encerra a dinâmica social num mecanismo determinista do qual apenas se sairia com um salto para o exterior, pura ilusão alienante. Como mostra Michael Löwy, a alienação, concebida como problema desde os primeiros escritos de Marx, possibilita-se pelo fechamento de um sistema, o que levaria a encontrar as condições de transformação apenas no exterior desse sistema (LOWY, 2002, p.43); no exterior invisível de uma soberania inalcançável.

Ora, brincando com Marx mas ainda em Marx, diríamos que o exterior, esse exterior alienante, esse exterior de onde nenhuma transformação concreta ocorre realmente é, para a criança, o mundo adulto, as regras adultas, o universo crescido e maturado onde as regras estão previamente feitas e exteriormente justificadas. 
ISSN- 1413-8638

E-ISSN - 2238-5533

v. 23 , n. 3, p. 170-188, 2018

\section{O BRINCAR DAS CRIANÇAS COMO “TRABALHO INDEPENDENTE”...}

Brincar é a atividade que as crianças melhor conhecem, de que mais gostam e está presente desde que se levantam até que se deitam, em todas as situações, mesmo que muitos adultos o desconheçam e ignorem. Este "trabalho de brincar"exige treino, muita atenção, energia... exige estar com outros, tempo e oportunidade para se exercer. Todos nós brincamos e todos sabemos como é mas quando tentamos teorizar ou falar no ato de brincar, entramos normalmente num discurso muito obtuso, por vezes quase "imbecil" como lembra Sutton-Smith (2001). Sabemos o que sentimos, mas mais difícil é valorizarmos uma vida em que se brinca e se aprende a brincar. De uma maneira geral os adultos consideram o brincar como algo 'dispensavel', ou seja, que pode ou não acontecer e de forma muito diferente quando se trata deles (adultos) ou quando se trata dos mais novos. Não negando a necessidade que as crianças tem de brincar, muitos adultos dão mais importância às atividades que consideram ter uma relação de interesse com os conteúdos escolares, em que a criança está sempre a ser orientada, 'vigiada' ou supervisionada, do que à atividade livre em meio aberto. Contudo, as brincadeiras são elementos essenciais de relação com a natureza (e com a sua natureza), e a cultura do mundo adulto e constituem a possibilidade de um desenvolvimento saudável e de reconhecimento de que as crianças não são um produto passivo do ambiente, mas sim agentes dinâmicos do mesmo (ARAÚJO, 2017).

No contato com a natureza as crianças estimulam todos os sentidos, descobrem o significado da vida e da liberdade, sentem-no na pele. Brincando ao ar livre as crianças aprendem com ideias que crescem: observam, ouvem, cheiram, mexem, tocam, exploram, recolhem, empilham, movem-se, correm, tropeçam, nadam, criam, inventam, transformam materiais, constroem brinquedos e jogos, respeitam, partilham com prazer o que descobrem querendo sempre mais. $E$, ao contrário do que se pode pensar, nestas descobertas as crianças precisam dos adultos e da sua colaboração. Contudo, colaboração não é imposição nem submissão.

O atual estado das coisas conduz a criança para a atividade produtiva (para o trabalho útil) desde a sua mais tenra idade.Em todos os discursos 
mediáticos, no Jardim de infância, na escola, em casa... tudo é feito para elas admitirem que mais tarde (no futuro) terão que produzir riqueza. Segundo estas regras, os adultos são seres dedicados ao trabalho e as crianças seres em "estado de adaptação" para o futuro que lhes foi traçado (GODDARD, 2007).

As crianças vivem rodeadas de propostas inibidoras da fantasia que constantemente se apodera delas, sem grande hipótese de escolher o mais belo dos sonhos como propunha o "utopista" Charles Fourier. Não existem crianças preguiçosas para a atividade lúdica, para brincar e, quando a fantasia delas se apodera, são infatigáveis. É só vê-las nas suas mais nobres expedições, correm, saltam e lembram-se do "diabo"..."os diabretes desafiam as geadas e as fadigas bem como os perigos" Fourier (2007,p. 41).

Aparecendo vulgarmente como atividade "gratuita" ligada à distração e irresponsabilidade a atividade de brincar é absolutamente necessária para 0 bem-estar de qualquer pessoa e mesmo que pareça "inútil" do ponto de vista imediato, brincar tem uma enorme importância para a aprendizagem, de todos os pontos de vista, em todos os contextos. Mas é preciso compreender que toda esta energia será um suplício se ordenada pelos pais ou professores.

Há práticas e práticas emuitas vezes se privam as crianças do contato com os animais, com as plantas, para depois lhes propor um filme, uns slides ou mesmo umas gravuras sobre os animais e as plantas... um pouco como sugeria Magritte “ceci n'est pas une pomme”,imagem não é a'coisa'.

É comum termos a preocupação de as incentivar ao estudo da natureza através da imagem (do desenho, da foto) e não da 'coisa', do papel e lápis, da cola e do recorte,da reciclagem, mas mais difícil é organizar o mundo de forma a que o possam explorar e aproveitar. A atividade independente - o brincar como trabalho independente - das crianças não tem nem reconhecimento, nem estatuto social. No entanto, o mundo da natureza é um laboratório em que ela se torna "cientista" e, hoje, as crianças estão conscientes das ameaças globais ao meio ambiente. Mas, se o contato físico, a intimidade com a natureza for desaparecendo...o que pode acontecer?

\section{ANTES DA RESPOSTA, VOLTEMOS A MARX.}


Nos célebres Manuscritos parisienses de 1844, Marx ensaia uma primeira sistematização dos conceitos de "alienação" e de "trabalho alienado". Uma vez mais, sublinhemos que o aparentemente sisudo Dr. Karl Marx não nos fala aqui de infância. Fala de outra coisa.

Fala, por exemplo, de uma centralidade do conceito de "economia política", que transitará anos mais tarde como subtítulo de O Capital. Os motores de tal conceito, para Marx, são os da ganância, da "guerra entre os avaros" e da "competição" (MARX, 1975, p.130). Parece aqui pressupor numa ponte possível para uma ideia anticapitalista de responsabilidade ambiental -, que a finitude das capacidades do solo é uma das condições da exploração capitalista, ao motivar a acumulação de recursos escassos e a exploração destes por apenas alguns (BENSAID, 2011, p.171). Ao/à trabalhador/a não cabe o fruto do seu trabalho. Este escapa-lhe, secundariza-o de tal maneira que quanto maior for a produção maior é a exploração. Aqui, o trabalho "desrealiza" (MARX, 1975, p.132) o trabalhador por não lhe pertencer, ao escapar-Ihe como se não the pertencesse. Marx fala-nos aqui de trabalho alienado, definindo essa alienação pelo modo como a natureza do trabalho e o seu produto escapam ao controle crítico de cada trabalhador/a. Nesta relação de alienação, o trabalho não beneficia o trabalhador porque é todo justificado externamente e é totalmente usufruído exteriormente. A atividade do/a trabalhador/a, nas palavras de Marx, "não é a sua atividade espontânea" (idem, 134). Separa-se atividade de espontaneidade, definindo-se o trabalho como uma forma de subjugação

Nunca Marx fala de crianças, mas não deixa de enviar uma mensagem encriptada ao modo como definimos a infância, como o seu tempo e a sua atividade se exercem fora da sua alçada e do seu arbítrio. Em Portugal, como em grande parte dos países ditos "desenvolvidos" do século XXI, as formas de imposição de trabalho às crianças, o modo como este se extrapola aos tempos do seu lazer, a negação de autonomia e de capacidade de gestão desse tempo parecem devolver a palavra de Marx no sentido de um outro pensamento da infância. 


\section{O TRABALHO DOS ALUNOS COMO "TRABALHO POR CONTA DE OUTRÉM"}

Em Portugal, as crianças vivem a várias velocidades e quase sempre a um ritmo muito acelerado. O seu tempo livre é marcado por uma agenda muito preenchida, com muitas atividades organizadas em função da atividade escolar e das ocupações e preocupações dos pais e encarregados de educação, o que torna o usufruto desse tempo, correlativo de liberdade, muito difícil para elas. $\mathrm{Na}$ verdade, a entrada para a escola é a entrada para o mundo do trabalho escolar, um mundo com horários muito rígidos, com uma estrutura organizacional tributária da estrutura do mundo produtivo, das formas de divisão do tempo e do trabalho típicas da sociedade industrial . O que habitualmente se designa, simplificadamente, por escola é, na verdade, uma organização complexa e diversificada de contexto para contexto, que continua a mobilizar expetativas coincidentes para muitas famílias, como a da esperança de uma vida melhor, não obstante as formações que disponibiliza já não serem, como foram, garantia de mobilidade social e/ou de emprego (ARAÚJO, 2018).

É na altura em que entra para a escolaque a criança assume o estatuto de ser social e passa a ter a condição de aluno/a, uma condição que exige compreender que o que está implícito, na escola, é uma aprendizagem marcada por um tipo específico de trabalho e de comportamento. Como refere Perrenoud (1996), na escola a criança desenvolve o ofício de aluno/a e assim como o/a professor/a exerce um ofício - na medida que tem um trabalho remunerado e reconhecido socialmente -, também podemos dizer que o aluno exerce um ofício.

Ser aluno é trabalhar na e para a escola, uma das ocupações permanentes mais reconhecidas, que em Portugal é exercido por todos, por obrigação e durante cerca de pelo menos doze anos de vida. O ofício de aluno é marcado por um tipo de ocupação que rompe com outras formas socializadoras como, por exemplo: brincar,entre outras aprendizagens que se faziam na esfera doméstica. Se o ofício de aluno/a parece ser mais sui generis do que outros, não é somente por não ser remunerado, mas sobretudo porque é marcado por algumas tensões: 
AMBIENTE \& EDUCAÇÃO

ISSN- 1413-8638

E-ISSN - 2238-5533

v. 23 , n. 3, p. 170-188, 2018

i) não é livremente escolhido;

ii) depende de terceiros (na medida em que para o aluno aprender, o professor tem de ensinar);

iii) exerce-se em permanente supervisão;

iv) está sujeito a uma avaliação das qualidades pessoais, mas também dos defeitos das pessoas, da sua cultura, da sua inteligência e do seu carácter (PERRENOUD, 1996) e é maioritariamente exercido em espaços fechados e sem contacto privilegiado com a natureza (ARAÚJO, 2018).

Paralelamente a isto, o prolongamento do estatuto de aluno/a para fora da sala de aula está legitimado pelo que é realizado no âmbito das atividades de enriquecimento curricular $\left(A E C^{5}\right)$, pelos trabalhos para casa $(T P C)^{6}$, entre outras situações, de que são exemplo as explicações. Aliás, a sigla TPC é muito utilizada pelas crianças para brincar e inventar outras designações: trabalho para carecas, trabalho para cábulas, trabalho para camelos, tortura para crianças, trabalho p'ra chatear etc., o que pode ser um indicador de uma reflexão crítica relativamente ao que significa este tipo de trabalho, para elas monótono, difícil, sem sentido e sem qualquer atrativo. A forma descontraída e humorística com que utilizam estas designações é uma maneira de relativizar e aceitar este tipo de trabalho, alienante e sem sentido, constituindo a subversão da designação pela manutenção das iniciais (TPC) uma forma de resistência simbólica e difusa a algo que normalmente sentem como hostil (ARAÚJO, 2007).

Quando a criança entra para a escola passa a ser um "trabalhador por conta de outrém", com muita dificuldade em fazer valer os seus direitos, nomeadamente o direito a jogar e brincar em contacto com a natureza e a escolher o que fazer no seu tempo livre. Uma prova disso são as horas que passa diariamente em espaços fechados e, ainda, as constantes notícias sobre se as crianças devem ou não fazer TPC nas férias, não se compreendendo

\footnotetext{
${ }^{5} \mathrm{Em}$ Portugal a sigla representa 'Atividades de Enriquecimento Curricular no âmbito da Escola a Tempo Inteiro'

${ }^{6}$ TPC em Portugal significa 'Trabalhos para Casa' mas na verdade são trabalhos escolares em casa ou em espaços e centros de explicações.
} 
que, em qualquer profissão, as férias são para descansar e não para trabalhar. É muito difícil para os alunos o trabalho de reprodução de tarefassemelhantes às que já fizeram na escola (ARAÚJO, 2009).

Torna-se interessante, por outro lado, traduzir a ideia de trabalho na gestão adulta do trabalho escolar, para melhor compreender o seu caráter alienante e adestrador. Quando a escola e a tarefa escolar modelam na criança o conceito de trabalho, fazem-no frequentemente num regime de total ausência de justificação ou dotação de sentido. Na atividade repetitiva, na ação "infantilizada", a criança vai obtendo incentivos que não consegue de todo justificar no eixo da sua linguagem e ação, como se isso a que se chama "trabalho" valesse por si próprio nas palavras de outrem.

Assim, a cada canção memorizada, palavra repetida ou gravura colorida de acordo com as regras, o reforço ouvido no "bom trabalho!" ou no "continua, muito bem!", o sentido da ação tem origem única no adulto, é propriedade exclusiva do adulto que a reforça. Trata-se de um "estímulo dependente" (GARCIA \& OLMEDA, 2017), mais tarde replicado na rentabilidade diferida do trabalho alienado. Um trabalho que, além de tudo o mais, não é contabilizado enquanto tal, o que se repercute no excesso em que é exercido.

As crianças ${ }^{7}$ entre os 6 e os 12 anos de idade trabalham hoje na e para a escola cerca de 8 a 9 horas diárias - ou seja, cerca de 40 a 45 horas semanais, se considerarmos que não o fazem de todo ao final de semana, o que nem sempre é verdade. Trabalham durante mais tempo do que aquele que é definido no horário de trabalho que achamos razoável para um adulto. A quantidade de tempo que passam, no seu tempo livre depois das aulas, a realizar atividades organizadas e prescritas pelos adultos (TPC, música, inglês, ginástica, desporto, etc.) sem, na maior parte das vezes, terem uma palavra a dizer, é considerada excessiva pelas próprias crianças, que ficam sem tempo

\footnotetext{
${ }^{7}$ De acordo com a Convenção dos Direitos da Criança: criança é todo o ser humano com menos de dezoito anos, exceto se a lei nacional confere a maioridade mais cedo. Ver: https://www.unicef.pt/actualidade/publicacoes/0-a-convencao-sobre-os-direitos-da-crianca/, acesso 19.11.2018.
} 
para brincar. O excesso vê-se, aliás, no cansaço que todos os dias vão mostrando na escola e fora dela (ARAÚJO, 2009).

Assim, as crianças aceitam as regras de um jogo que não foi com elas negociado, pois não o aceitarem pode condicionar as suas vidas e, portanto, o seu "sucesso". Aliás, como diria Bourdieu, é esta crença e aceitação das regras do jogo (a illusio) a condição da sua perpetuação. Este tipo de trabalho não parece contribuir para o seu bem-estar e auto-estima, nem sequer para o seu sucesso. No entanto, compreendemos que o assumem como fundamental para não terem aborrecimentos, obter reconhecimento, uma nota ou passar no final do ano. Para muitas crianças, os estudos tornam-se, assim, um mal necessário, uma etapa a transpor, esperando a verdadeira vida anunciada, no futuro e sempre para depois da escola.

Se fizermos um exercício de memória, reconheceremos que historicamente uma das lutas mais importantes do movimento dos trabalhadores foi pela redução do tempo total de trabalho, feito por duas vias principais: a conquista de férias, e de férias que haveriam de ser remuneradas (reduzindo assim o tempo de trabalho anual), e a redução do horário semanal de trabalho que, na maioria das sociedades industriais avançadas, haveria de ser imposto por lei, estabelecendo o limite máximo de horas que era possível exigir por semana nos horários normais de trabalho. Mas, apesar destes antecedentes históricos, no século XXI ainda não conseguimos entender-nos nem sobre a dinâmica do tempo social, nem sobre as propriedades específicas do fenómeno do lazer e do tempo livre, bem como as suas principais implicações para os adultos e sobretudo para as crianças. E é talvez por isso que, apesar de termos lutado coletivamente por menos horas de trabalho para os adultos, estamos a sobrecarregar as nossas crianças com mais trabalho e mais esforço, fazendo com que elas tenham tempos de trabalho excessivamente prolongados e garantindo a ocupação tão integral quanto possível daqueles seus tempos que, de forma algo cínica, continuamos a designar como "tempos livres". E, assim, esta incompreensível preocupação dos educadores vai caminhando no sentido contrário daquele que nos apontava a evolução histórica, que era o de uma progressão contínua do 
tempo disponível. Mas, apesar do argumento de que atribuir às crianças mais tempo de trabalho seria para o seu bem, o trabalho escolar formal ou o trabalho escolarizado, sendo muito importante, não deveria ter uma carga horária tão ou mais pesada do que a que tem a ocupação laboral dos adultos.

Notemos que uma das mais presentes formas de opressão do capitalismo tem a ver com a "extração do sobretrabalho", isto é, com a inversão do tempo opressivo de trabalho sobre todas as dimensões da vida quotidiana, inclusive o tempo livre (ANTUNES, 2013, p.175-177). No caso das crianças, os dispositivos educacionais preparam frequentemente o terreno para esta invasão, colocando o próprio tempo livre ao serviço de uma ideia de produtividade orientada para a proliferação de uma atividadeque se autojustifica. Este mecanismo, no caso da criança, é invasor e adestrador. Coloca a criança em estado de permanente ocupação, desapossando-a do seu próprio tempo com uma sobreatividade disfarçada de oportunidades e de privilégio social. Sem o seu acordo, sem que a sua rede de atuação Ihe faça um sentido evidente, encontramos a criança do século $\mathrm{XXI}$ enredada num processo feérico de atividades escolares ou extraescolares (note-se neste termo a insistência na referência à escola), sem que esta tenha verdadeira apropriação desse processo. Inserida numa contemporaneidade avessa ao ócio, a dotação de sentido deste processo é frequentemente engendrada do exterior, instigando individualismo, competitividade e uma espécie de autojustificação do tempo ocupado, como se este valesse por si mesmo. Prepara-se assim o terreno para uma realidade adulta em que uma espécie de moral opressiva do sentido do trabalho prolifera, fora do alcance crítico de quem realmente o exerce.

É neste sentido que propomos pensar o ofício de aluno (comparando-o metaforicamente ao trabalho por conta de outrém ou subordinado, em que os tempos, os locais e os instrumentos de trabalho são definidos pelo patrão) como apenas uma das componentes do ofício de criança (comparável nesta linha ao trabalho independente, em que o próprio é que define quando e como faz, tendo contudo de apresentar resultados). O tempo de trabalho letivo é hetero-definido mas, em todo o tempo restante, as crianças devem poder 
escolher livremente em função das propostas lúdico-expressivas que lhes forem disponibilizadas e, sobretudo, devem poder brincar como, aliás, está previsto na Declaração dos Direitos da Criança.

\section{SUBVERTER A ORDEM DAS COISAS}

Antes de prosseguir, adiantemos alguns princípios educacionais genéricos que nos possam permitir subverter a ordem das coisas. Centra-se este princípio de subversão especificamente na escola, enquanto principal instância disciplinadora no registo que vimos criticando. Esta ideia subversiva geral, entroncando na intenção de uma outra abordagem da educação e da escola, passaria por pelo menos três eixos genéricos principais, relacionados entre si:

- Um eixo relacional, que garanta horizontalidade entre todos os agentes educativos, com o centro nos/nas alunos/as. As pessoas não são ilhas isoladas, nem planetas gravitando em órbitas diversas. As pessoas constroem sentidos e significados de modo relacional, sendo em relação que encaram e resolvem a dimensão inerentemente conflitual assumida em toda a experiência educativa. Há que assumir, assim, uma lógica cooperativa e comunitária nas relações de aprendizagem, desobedecendo à relação tradicionalmente vertical entre professor e aluno. Uma relação que não esgota o espectro educativo nem transborda abusivamente a sua esfera de ação.

- Um eixo epistemológico, que permita conceber os saberes de modo significativo, lúdico e livre. Um/a aluno não é um elemento desprovido de saberes e de experiências prévias, não é um/a reprodutor/a, não é uma máquina de repetição e de reprodução de conhecimentos sem contexto. Os saberes, por outro lado, não são dimensões fragmentadas e espartilhadas em "disciplinas" espacial, temporal e hierarquicamente organizadas. É preciso reassumir pedagogicamente o princípio de John Dewey, segundo o qual a exploração de um problema a pesquisar conjuntamente é preferível ao privilégio da solução. O "impulso construtivo" (DEWEY, 2002, p.47), alimentado por espaços, por materiais e por modalidades de convívio com os saberes que não se resumam à passividade reprodutora são um desígnio fundamental. Tal 
como, no que toca aos saberes, subverter a ordem escolar implica a dimensão coletiva desses saberes em vez do cinzentismo solitário da sala de aula. Num sentido próximo ao de "comunidade de investigação", que Lipman quis fornecer como alternativa ao de sala de aula, em que "os alunos dividem opiniões com respeito, desenvolvem questões a partir das ideias dos outros, desafiam-se entre si para fornecer razões a opiniões até então não apoiadas. Uma comunidade de investigação tenta acompanhar a investigação pelo caminho que esta conduz ao invés de ser limitada pelas linhas divisórias das disciplinas existentes" (LIPMAN, 1991, p.31). Por outro lado, claro, a escola não esgota o eixo dos saberes na esfera educacional.

- Um eixo social e político, que assume a Escola como um local de encontro e de diversidade social. Para que esta diversidade se concretize e se equilibre é necessário assumi-la como um valor, não como um problema, evitando a uniformização que frequentemente cria falsas igualdades (considerando o desequilíbrio de oportunidades, de proveniências e de culturas), e dotando as diferentes vozes destas desigualdades de poder deliberativo, decisório e responsabilizado. Há que assumir, igualmente, a porosidade entre Escola e Comunidade, reconhecendo diferenças mas, acima de tudo, pressupondo uma política de abertura de portões do espaço escolar a um espaço comunitário, também ele educativo, que importa articular de acordo com projetos coerentes.

\section{DEVOLVER A NATUREZA ÀS CRIANÇAS E AS CRIANÇAS À NATUREZA: UM PROJETO COERENTE}

Sem ser um especialista em ciências naturais ou teorizar sobre questões ambientais, Marx foi um dos primeiros a reconhecer a importância de grandes descobertas como, por exemplo, a teoria darwinista. A 'teoria da evolução' biológica proposta por Darwin, encontra paralelo com a 'teoria marxista' da evolução social.

Ao longo da história, as civilizações nasceram e expandiram-se numa relação complexa pelo que o que acontecer de hoje para o futuro é, como refere Patel e Moore (2018), imprevisível e paradoxalmente, inteiramente previsível. Independentemente do que os seres humanos decidirem fazer, 
haverá mudanças irreversíveis na 'rede da vida'. Para enfrentar estas mudanças precisamos de seres humanos altamente preparados. É fundamental que as crianças se desenvolvam em ambientes naturais, ambientes verdes e desenvolvam consciência politica e ecológica.As crianças, sendo privadas do contato com a natureza, do contato com outras espécies, terão dificuldade em construir um pensamento sistémico e inovador de respeito pelo ambiente pois nele e com ele não brincam. Tenderão, maioritariamente, a ser consumidoras não reflexivas.

Paralelamente a isto, na sociedade contemporânea, as novas condições de vida ligadas ao consumo e à evolução e formas de vida quotidiana das famílias nos meios urbanos afetam o uso dos espaços e o contato com a natureza. A ansiedade dos pais sobre os lugares em que as crianças crescem e brincam, sobretudo se for em espaço aberto, deve-se ao fato de os percecionarem como inseguros. Parece necessário que os pais ensinem os seus filhos a gerir as situações de risco como forma de garantir que as crianças percebem e controlam as suas ações nos diferentes locais de que podem usufruir (ARAÚJO, 2012) num respeito pela natureza.

Se aproveitar de um modo conhecedor (culto) as oportunidades que a aprendizagem escolar (formal) e o lazer propõem fossem igualmente distribuídas, não haveria um conflito entre os objetivos educativos e lúdicos, entre estudar e brincar, entre brincar em espaços fechados e exíguos e brincar ao ar livre. As atividades em contacto com a natureza contribuem para o bemestar das crianças (e adultos) e logo para o seu sucesso na escola ou fora dela. Precisamos devolver a natureza às crianças e as crianças à natureza como estratégia de Educação Ambiental que contribui para o sucesso de vida.

\section{PARA TERMINAR OU CRIAR UM NOVO COMEÇO?}

Chegados aqui, podemos fazer um simples exercício: fechamos os olhos e vemos os nossos vizinhos a sair de casa com os filhos/as, uma mãe atarefada, num stress 'assustador' abre a porta, corre, põe os filhos na cadeira de trás, falta o lanche, volta a casa põe o cintodá uns berros para um que se atrasou e corre com a sandwich na boca, ainda a apertar o casaco, outro a 
fechar a mochila olha o livro, olha a porta e, num pior cenário, vamosperder 0 autocarro ou o metro, ajuda o teu irmão... Falta sempre qualquer coisa, um corre-corre "sonorizado", sem silêncios e vontades permitidas. Reduzir a velocidade dos seres humanos não é tarefa fácil, pelo menos não é tão fácil como acelerá-la.

Voltando à teoria de Marx e à sua descoberta da teoria darwinista, apercebemo-nos da complexidade da evolução da espécie e da evolução social. Se a velocidade que nos caracteriza é baseada no stress social, a velocidade nos animais é baseada nas suas características biológicas: as asas de um inseto movem-se muito depressa e os nossos olhos não acompanham o seu ritmo, a tartaruga pode levar um dia inteiro a atravessar uma rua ou um relvado e que dizer do movimento das plantas?

Talvez seja mesmo a velocidade, o ritmo e a pressa de consumir o tempo, ou o que quer que seja, que marca a rotina quotidiana da maior parte das crianças, que as submete a uma vida "de trabalho útil": levantar, vestir, tomar o pequeno almoço (quando ele existe), sair à pressa, vociferar, dar e receber indicações para que tudo se encaixe com rapidez, mas não respeitando o seu ritmo biológico a sua natureza. Trabalhar para o futuro começa em cada manhã, em todas as manhãs e em quase todos os espaços domésticos e aumenta quando as suas vidas se abrem ao espaço público da vida agitada.

Estes comportamentos são uma forma de interrogação interacional num espaço público de conflito de normas entre a cultura dominante e as diferentes subculturas produzidas pelos diferentes grupos. É possível tornarmo-nos por outro(s) e desempenharmos o seu papel, implicarmo-nos num jogo de circunstâncias, como refere Goffman (1993). Existe uma relação entre os indivíduos e os papéis por eles assumidos na interação, e essa relação é uma resposta ao sistema interativo em que esses papéis são desempenhados. Neste sentido, a escola é um espaço onde vida pública e privada são coexistentes, onde se descobrem os pormenores da vida quotidiana, um espaço público onde se espera que as pessoas representem a sua vida 
privada. A forma como as pessoas se vestem, pela manhã, para trabalhar, levar os filhos à escola ou ir à padaria, testemunha o percurso diário, expondo cenas da vida doméstica e faz antever a razão pela qual, como propunha Marx, a luta pela sobrevivência da vida ou da espécie é tão importante.

Perante a rotina que nos é imposta, muitas vezes nos sentimos presos como que numa camisa-de-forças que parece limitar, aumentando a necessidade de desobediência. O tempo das crianças é fortemente marcado pelos tempos e ritmos dos adultos e a principal característica desse tempo das crianças é ser monopolizado como um tempo escolarizado, aproveitado do ponto de vista educativo e social, constituindo-se assim para elas num tempo não livre por forçada ocupação e submissão.

Em casa, no ATL, na escola ou em qualquer outro espaço educativo, não se trata de lhes organizar a vida, trata-se de fazer com que as crianças compreendam a sociedade em que vivem e consigam adquirir os instrumentos para lidar com ela, tendo em conta os constrangimentos com que se deparam diariamente. Pessoas felizes, como dizia Marx quando o desafiaram a refletir no seu exame final de língua alemã no Ginásio de Trèves - "como escolhe um jovem a sua profissão?..."

O título deste texto alude, obviamente, ao fim de O Manifesto de Marx e Engels, em que se encorajava a unidade do movimento operário como contraponto das estratégias divisionistas - explícitas ou implícitas - que lhe toldavam a eficácia. Centrar este apelo nas crianças significa mais do que o mero gosto da alusão. Significa, antes de tudo, reconhecer e ultrapassar a imposição da vontade adulta sobre o universo infantil. Esta ultrapassagem, sem se traduzir numa ingénua idealização da criança, passa antes de mais pelo reconhecimento dos seus direitos, do seu direito ao lazer e da autonomia do brincar. Os processos de despossessão, que subalternizam as crianças e cada criança como se fossem propriedade exclusiva da família (MONTEIRO \& ARAÚJO, 2016, p.74), tornam a infância uma etapa em que cada elemento se define como uma espécie de mercadoria provisória; as crianças tornam-se "parcelas de negócio ou simples componentes de sistema" (idem, 77), sendo 
cada fração da sua vida segmentável num mecanismo de trocas em benefício de um adulto futuro. O apelo à união de todas as crianças torna-se, reconhecendo este cenário, num apelo à unidade harmoniosa de cada criança: é preciso unir, no sentido de unificar cada criança, que não é um conjunto de parcelas mas uma unidade produtora de voz e de sentido. Crianças de todo o mundo, uni-vos! A criança deve unir-se em si mesma, união que pressupõe a ligação eco-lógica com o seu próprio espaço e ambiente.

Toda a reflexão que fomos desenvolvendo mostra a necessidade de se considerar a atividade de brincar como ato sério, próprio de cada idade da vida, do respeito pela natureza e pela natureza de cada ser humano. Mostra ainda como a função dos/as educadores/as não é dar, deliberadamente, acesso à cultura, ou a mais cultura, mas sim dar os meios para que as crianças se possam exprimir e experimentar novas formas de olhar o mundo interagindo com ele. É neste sentido que apelamos à responsabilidade dos adultos (de todos nós) para criar infâncias de agradáveis lembranças valorizando a utilidade desse tempo "inútil", do ócio edo lazer -um tempo socialmente disponível, liberto de interesses económicos nas palavras de Marx -, um tempo de liberdade para brincar e jogar fundamental para que as crianças sejamcrianças felizes e participativas.é que os pedagogos têm levado demasiado tempo a interpretar a educação de maneiras diferentes; caberá às crianças transformá-la?!

Para a transformarterão de se unir eunir-se em todo o mundo!

\section{REFERÊNCIAS BIBLIOGRÁFICAS}

ANTUNES, Ricardo. Os sentidos do trabalho. Ensaio sobre a afirmação e a negação do trabalho. Coimbra: Almedina, 2013.

ARAÚJO, Maria José. "O trabalho das crianças: do «trabalho independente» ao 'trabalho por conta de outrém' ». Plataforma Barómetro Social. FLUP. 2018

ARAÚJO, Maria José. "Brincar no Bairro: descobrir o lazer no tempo livre através da sociabilidade nos espaços de logradouro" in Paulo P.; António C.; 
Susana V.; Pereira, B. (Org.). Educação Física, Lazer \& Saúde. Perspetivas de desenvolvimento num mundo globalizado. Porto: ESE-IPP, 78-87. 2017.

Araújo, Maria José. Crianças Ocupadas. Como algumas opções erradas estão a prejudicar os nossos filhos. Lisboa: Prime Books. 2009

Barrère, Anne.O Trabalho dos Alunos. Porto:Rés-editora, s/d.

Bourdieu, Pierre. La Distinction, Critique Sociale du Jugement, Paris: Minuit, 1979.

Bensaid, Daniel. Marx ha vuelto. Barcelona: Edhasa, 2011.

Bauman, Zygmunt. A liberdade. Lisboa: Editorial Estampa, 1989

Bensaid, Daniel. Marx, manual de instruções. São Paulo: Boitempo Editorial, 2013.

Bensaid, Daniel. Marx, o intempestivo. Lisboa: Combate, 2014.

Bourdieu, Pierre e Passeron, Jean-Claude (s/d) A Reprodução: elementos para uma teoria do sistema de ensino. Lisboa: Veja. (s/d).

Dewey, John. Democracia e Educação. Lisboa: Didática Editora. 2007

Fourier,Charles. A Infância Emancipada. Lisboa: Antigona. 2007

Godard, Philippe. Au travail les enfants! Paris: Éditions Homnisphères. 2007

Goffman, Erving. A Apresentação do Eu na Vida de Todos os Dias. Lisboa: Relógio d'Água,1993.

Gorz, André. Métamorphoses du Travail. Quête du Sens. Paris: Éditions Galilée. 1988.

Lowy, Michael. A teoria da revolução no jovem Marx. Petrópolis: Vozes, 2002.

Marx, Karl. Escritos de juventude. Lisboa: Edições 70, 1975.

Marx, Karl. "Teses sobre Feuerbach". In: Obras Escolhidas. Lisboa: Avante, 
1982. p. 1-3.

Marx, Karl.; Engels, F. A Ideologia Alemã. Lisboa: Editorial Presença, 1976.

Monteiro, Hugo.; Araújo, Maria José. "Crianças à espera? Um ensaio sobre participação na cidade". Sensos, v. VI/ 1, p. 71-82, 2016.

Patel , Raj.; Moore, Jason. A História do Mundo em Sete Coisas Baratas. Um guia sobre capitalismo, natureza e o futuro do planeta. Lisboa: Editorial Presença. 2018

Perrenoud, Perrenoud. Ofício de Aluno e Sentido do Trabalho Escolar. Porto: Porto Editora,1996.

Sutton-Smith, B. [(2001) 1997]. The ambiguity of play. London: Harvard University Press. 